\title{
Growth of Dendranthema xgrandiflorum (Ramat.) Kitamura under Various Spectral Filters
}

\author{
M.J. McMahon, J.W. Kelly, and D.R. Decoteau \\ Department of Horticulture, Clemson University, Clemson, SC 29634 \\ R.E. Young and R.K. Pollock \\ Department of Agricultural Engineering Clemson University, Clemson, SC 29634 \\ Additional index words. phytochrome, morphology, red light, far-red light, photomorphogenesis, chrysanthemum
}

\begin{abstract}
Spears' (nonpinched and pinched) and 'Yellow Mandalay' (pinched) chrysanthemums were grown in growth chambers equipped with panels filled with liquids that served as spectral filters. Light quality was altered by reducing blue light, increasing red : far-red (R : FR) light, or reducing $R$ : FR. Control panels did not selectively alter light transmission. Photosynthetic photon flux was the same in all chambers. All plants grown under increased R: FR filters had reduced height, reduced internode length, and increased chlorophyll content compared to controls. Reduction in blue light decreased chlorophyll content of pinched plants compared to controls. Pinched plants grown under increased R : FR light and !ong days developed fewer nodes than controls due to the formation of abnormal capitula; the controls and plants from the other treatments developed more nodes before producing similarly abnormal capitula. Stem diameter and leaf area did not differ due to treatments.
\end{abstract}

Chemical growth regulators are often used to maintain desired growth and form of potted chrysanthemums. However, increasing awareness of the impact of chemicals on the environment and strict U.S Environmental Protection Agency regulations may limit or prohibit the use of many of these chemicals. For example, butanedioic acid mono(2,2-dimethylhydrazide) (daminozide, B-Nine, Alar) is frequently used to control potted chrysanthemum height. The use of daminozide on edible crops was recently prohibited.

Light quality has been demonstrated to influence many aspects of plant growth and morphology (Borthwick and Cathey, 1952; Borthwick et al., 1952; Mortensen and Strømme, 1987; Vince-Prue and Canham, 1983). Phytochrome, the primarypigment controlling photomorphogenesis, has two forms, $\mathrm{P}_{\mathrm{r}}$, and $P_{f r}$, which have peak absorption in red $(660 \mathrm{~nm})$ and far-red wavelength $(730 \mathrm{~nm})$ light, respectively. Upon absorption, a phytochrome chromophore converts to the other form (Borthwick et al., 1952). Light quality determines phytochrome equilibrium $(\phi)$ in vivo, which, in turn, determines plant morphology (Holmes and Smith, 1977). Phytochrome equilibrium is often expressed as the ratio of $\mathrm{P}_{\mathrm{fr}}$ to total phytochrome $\left(\phi=\mathrm{P}_{\mathrm{fr}}\right.$ : $\left.P_{\text {tot }}\right) . P_{\text {fr }}: P_{\text {tot }}$ is determined by integrating the quantitative effects of all wavelengths between 350 and $850 \mathrm{~nm}$ on phytochrome equilibrium (Sager et al., 1988).

A plant canopy acts as a selective filter that absorbs red (R) and blue (B) but is relatively transparent to FR (Kasperbauer, 1988). Under a leaf canopy, plants receive light with a decreased $R$ : FR or reduced $\mathrm{P}_{\mathrm{ft}}$ : $\mathrm{P}_{\text {toc }}$ compared to full sunlight. These plants are generally taller and have a different chloroplast arrangement than plants grown in full sun (Eskins and Duysen, 1984; Kasperbauer, 1988). Plants receiving a relatively low $\mathrm{R}$ : FR also exhibit longer internodes, less branching, and larger and thinner leaves (Kasperbauer, 1988).

Received for publication 29 May 1990. South Carolina Experiment Station paper no. 3170. Support for this project was provided by South Carolina Agricultural Experiment Station (SCAES) Ornamental Horticulture Research Funds; Yoder Bros., Pendleton, S. C.; and Fafard, Anderson, S.C. The use of trade names does not imply endorsement of SCAES of the products named, nor criticism of similar ones not mentioned. The cost of publishing this paper was defrayed in part by the payment of page charges. Under postal regulations, this paper therefore must be hereby marked advertisement solely to indicate this fact.
Since phytochrome absorbs in the B region (400-500 nm) as well, B may also affect plant morphology by influencing phytochrome or another, unidentified photoreceptor (cryptochrome) that affects plant morphology (Duell-Pfaff and Wellmann, 1982). Dritz and Sager (1990) reported that soybeans grown under a blue-deficient, narrow-band light source resembled shaded plants.

Materials that selectively filter out specific radiation wavelengths entering a greenhouse may allow manipulation of plant growth. Mortensen and Strømme (1987) grew several plant species under selective spectral filters. Plants continually grown with increased R : FR were shorter and darker green with more branches, but had smaller leaves and lower dry weights than those grown in reduced R : FR. More information is needed on the effects of altered spectral radiation on the growth and development of floricultural crops. This study was conducted to determine the effects of B-, R-, and FR-filtered light on two commercial, pinched pot chrysanthemums, 'Spears' and 'Yellow Mandalay'.

\section{Materials and Methods}

General procedures. Ten growth chambers were constructed in house as an attached lean-to on the side of an existing greenhouse. The glass wall on the south side of the greenhouse was removed and vertical aluminum panels were installed $55 \mathrm{~cm}$ apart and $2.5 \mathrm{~cm}$ from the bottom of the chambers at each glazing bar, forming reflective walls for each chamber. The bottom of the chambers was a continuous aluminum pan that was the width and length of all 10 chambers. A 7-cm-wide strip of flat black paint was applied to the pan centered beneath each vertical wall to prevent light from reflecting between adjacent chambers. The back of the chambers was a sheet of black polyethylene between two layers of white polyethylene that could be rolled up to allow access to the chambers. The front of each growth chamber was a $54 x 140-\mathrm{cm}$ sheet of transparent hollow polycarbonate with cross sections of columns $6 \mathrm{~mm}$ deep and $11 \mathrm{~mm}$ wide (Polygal, Janesville, Wis.) treated for resistance to ultraviolet (UV) radiation and sealed at one end with caulking compound. A fan located at the top of each growth chamber

Abbreviations: B, blue; FR, far red; P, phytochrome; PPF, photosynthetic photon flux; R, red; UV, ultraviolet. 
circulated air from the attached greenhouse through each unit. The greenhouse air was heated or cooled to modulate temperature in the chambers. Thermistors in each chamber were connected to a computer and provided constant monitoring of chamber temperature. Plants were placed in each chamber on a white plastic grid with $1.75 \times 1.75-\mathrm{cm}$ openings (manufactured for use as a diffusing panel for fluorescent light fixtures). The plastic grid was secured $14 \mathrm{~cm}$ below the edge of the pan. Pollock et al. (1990) thoroughly describe the chambers used.

The polycarbonate panel channels were filled with solutions chosen for their spectral filtering properties and resistance to photodegradation. The spectral filter solutions were a red dye \#259 (CIBA-GEIGY, Greensboro, N.C.) that filtered out much of the $\mathrm{B}$ and green light, a blue dye \#178 (CIBA-GEIGY) that filtered much $\mathrm{R}$ but not $\mathrm{FR}$, and $\mathrm{CuSO}_{4} \cdot 5 \mathrm{H}_{2} \mathrm{O}$, which filtered a greater proportion of FR than $\mathrm{R}$ light. Two controls were used, water- and air- (normal content of the panels) filled panels. Data from representative spectroradiometer scans of the selective filtering solutions and full sunlight are shown in Fig. 1. Scans of the controls (between 330 and $850 \mathrm{~nm}$ ) differed from full sunlight only in intensity (data not presented). The percent transmission for each of the selective filters (compared to full sun) is presented in Fig. 2. $\mathrm{R}$ : FR ratios (narrow and broad band) and $\mathrm{P}_{\mathrm{fr}}: \mathrm{P}_{\mathrm{tot}}$, determined from the formulas of Sager et al. (1988), varied in a similar manner for all treatments (as R : FR increased, $\mathrm{P}_{\mathrm{fr}}: \mathrm{P}_{\mathrm{tot}}$ increased) (Table 1); therefore, description of the light environment for most of the remainder of this paper will be as $\mathrm{R}$ : FR because this measurement is more easily obtainable for researchers who do not have access to a spectroradiometer.

For most experiments, the 10 chambers allowed two replications of each of five treatments. For the remaining experiments, eight chambers were used and only four treatments were evaluated (two replications of each treatment). All experiments were repeated.

All concentrations of the spectral filtering solutions were adjusted to provide similar photosynthetic photon flux (PPF) transmission, i.e., a $40 \%$ to $45 \%$ reduction in PPF through the panels. The $\mathrm{CuSO}_{4} \cdot 5 \mathrm{H}_{2} \mathrm{O}$ solution $(16 \%$, w/v) was the PPF reference for all other treatment concentrations. A gray, neutral-density

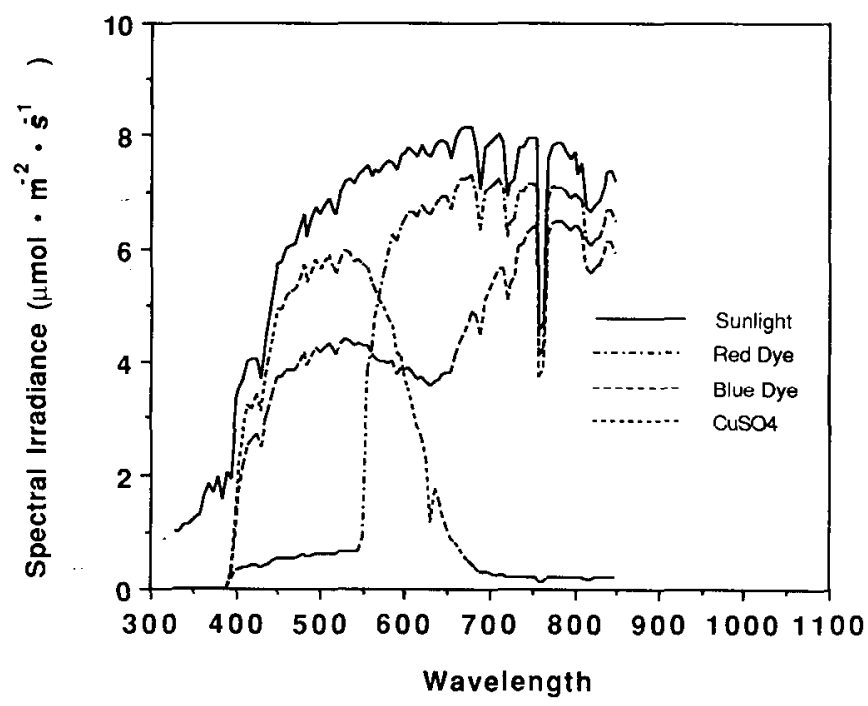

Fig. 1. Representative spectral scans of the selective filters and full sun. The scans were taken at about solar noon under cloudless conditions. The graph is representative only, the full sun spectrum is not the appropriate reference for all the other spectrums shown.

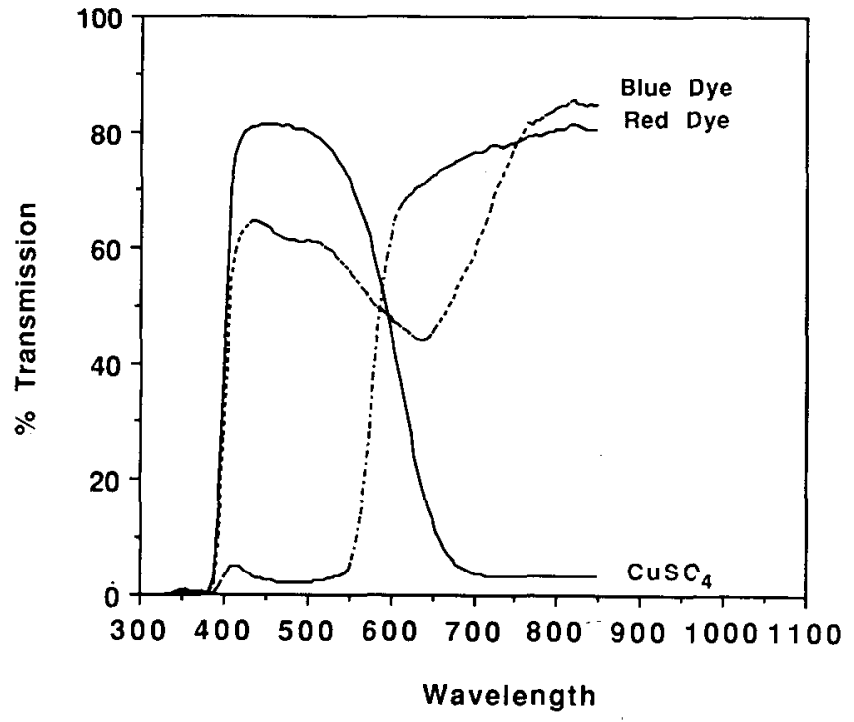

Fig. 2. Transmission characteristics of blue dye \#171, red dye \#259 (CIBA-GEIGY, Greensboro, N.C.), and $\mathrm{CUSO}_{4} \cdot 5 \mathrm{H}_{2} \mathrm{O}$.

Table 1. Ratios of $R: F R$ and $P_{f r}: P_{t o t}$ as influenced by spectral filters. Narrow-band R : FR measured as 655 to $665: 725$ to 735 $\mathrm{nm}$. Broad-band R : FR measured as 600 to $700: 700$ to $800 \mathrm{~nm}$. $\mathrm{P}_{\mathrm{fr}}: \mathrm{P}_{\mathrm{tot}}$, measured from 350 to $850 \mathrm{~nm}$.

\begin{tabular}{lccc}
\hline \hline & \multicolumn{2}{c}{$\mathrm{R}: \mathrm{FR}$} \\
\cline { 2 - 3 } Filter & Narrow band & Broad band & $\mathrm{P}_{\mathrm{ft}}: \mathrm{P}_{\text {tot }}$ \\
\hline Red dye & 1.16 & 1.03 & 0.71 \\
Blue dye & 0.99 & 0.70 & 0.66 \\
$\mathrm{CuS} \mathrm{O}_{4}$ & 3.30 & 7.20 & 0.79 \\
Air & 1.16 & 1.05 & 0.71 \\
Water & 1.16 & 1.05 & 0.71 \\
\hline
\end{tabular}

shade material was placed over the control panels to provide an equal reduction in PPF. All light measurements were made with an LI-1800 spectroradiometer equipped with a LI-1800-10 remote cosine sensor (LI-COR, Lincoln, Neb.). Light measurements were taken at about solar noon on cloudless days. Measurements were expressed as percentage of full sun. PPF measurements were also taken with a LI-COR LI-185-B quantum sensor. Quantum sensor readings were slightly higher because the cut-off at 400 and $700 \mathrm{~nm}$ is not as sharp as with the spectroradiometer; however, percent transmission was unchanged. Although PPF is a single measurement over a wide $(300 \mathrm{~nm})$ band width and was equal for all treatments, the wavelengths contributing to PPF varied greatly among selective filters (Fig. 1). The differences resulted in different levels of photosynthetically active radiation among chambers (McCree, 1972).

Influence of spectral filters on nonpinched 'Spears' chrysanthemums (Expt. 1). Five adjacent growth chambers were one replication (block) and the next five were the second replication (block) with the treatments randomly assigned to each replication. Spectral qualities of the panels were checked weekly. The red and blue dye solutions were replaced every 2 weeks because preliminary experiments indicated that red dye had changed spectrally after 3 weeks and the blue dye after 4 weeks. Copper sulfate was changed at the end of each experiment.

Forty uniform, rooted 'Spears' cuttings (Yoder Bros., Pendleton, S.C. $)$ were planted individually in $11.25-\mathrm{cm}\left(550 \mathrm{~cm}^{3}\right)$ square, opaque, green geranium plastic pots (Spartan Plastics, 
Spartanburg, S.C.) containing commercial potting media (Fafard \#3B; Fafard, Anderson, SC.). Four pots were placed in each chamber on 27 Apr. 1989. The plants were fertilized every other day with 300N-132P-249K (mg.liter ${ }^{-1}$ ) (from Peter's 2020-20; Peter's, Fogelsville, Pa.) for the first week and then with a solution of $0.0026 \mathrm{~N} \mathrm{KNO}_{3}$ and $0.0073 \mathrm{~N} \mathrm{CaNO}_{3}$ until the experiment was terminated. Water was applied as needed between fertilizations. All pots received the same fertilizer/water regime. Temperatures in the chambers ranged from a night average of $18 \mathrm{C}(\mathrm{SE} \pm 0.1)$ to a day average of $28 \mathrm{C}(\mathrm{SE} \pm 0.4)$; the 24-h mean was $24 \mathrm{C}$ ( $\mathrm{SE} \pm 0.3$ ). Light intensity in the chambers was $55 \%$ to $60 \%$ of natural light (natural light is $\approx 1700$ $\mu \mathrm{mol} \cdot \mathrm{m}^{-2} \cdot \mathrm{s}^{-1} \mathrm{PPF}$ on a clear day at solar noon in South Carolina).

Plants were not pinched. The experiment was terminated on 10 May. Data were collected on plant height above pot rim, chlorophyll content, number of leaves, stem diameter, internode length, and leaf area. Chlorophyll was extracted by the method of Moran and Porath (1980). Five leaf disks (0.28 $\mathrm{c} \mathrm{m}^{2} /$ disk) from each plant (one disk from each of the most recently expanded leaves) were removed, chlorophyll was extracted in $N, N$ - dimethylformamide for 48 to $72 \mathrm{~h}$ in darkness at $4 \mathrm{C}$ (five disks $/ 7 \mathrm{ml}$ ), and absorbance measurements were made with a Spectronic 1001 (Bausch and Lomb, Rochester, N.Y.). Chlorophyll content was calculated by the formulas of Moran (1982). Stem diameter was measured between the seventh and eighth nodes. Because compact internode lengths of $\mathrm{CuSO}_{4}$-filter-grown plants were difficult to measure, internode length was measured as the average length between the seventh and ninth nodes. Leaf area was measured using a LI-COR Leaf Area Meter Model 3100. Polycarbonate panels were cleaned, randomly filled with solutions or air, replaced randomly as described previously, and the experiment was repeated on 18 May 1989, terminating 31 May.

Influence of spectral filters on pinched 'Spears' chrysanthemums (Expt. 2). Experimental conditions were the same as Expt. 1, except plants were placed in the chambers on 15 May 1989 and pinched to five nodes 9 days later. Temperatures in the chambers ranged from a night average of $18 \mathrm{C}(\mathrm{SE} \pm 0.2)$ to a day average of $27 \mathrm{C}(\mathrm{SE} \pm 0.5)$. The $24-\mathrm{h}$ mean was $24 \mathrm{C}$ ( $\mathrm{SE}$ \pm 0.2 ). The experiment was terminated 15 June. Data collected were height of tallest shoot above pot rim, leaf chlorophyll content, stem diameter between third and fourth node of terminal lateral branch, internode length (average length from the third to fifth nodes) of terminal lateral branch, number of leaves on terminal. lateral branch, and leaf area. A leaf disk was taken from each of the five most recently expanded leaves from the terminal lateral branch and chlorophyll was extracted and analyzed as already described. The experiment was repeated on 13 June and terminated 22 July.

Influence of spectral filters on pinched Yellow Mandalay' chrysanthemums (Expt. 3). Experimental conditions were the same as for Expt. 2, except 'Yellow Mandalay' was used (Yoder Bros.). Temperatures in the chambers ranged from a night average of $19 \mathrm{C}(\mathrm{SE} \pm 0.3)$ to a day average of $28 \mathrm{C}(\mathrm{SE} \pm 0.5)$; the 24-h mean was $23 \mathrm{C}$ ( $\mathrm{SE} \pm 0.2$ ). Because no differences between air- and water-filled control chambers had been observed in the first two experiments, only water-filled panels served as controls for this experiment. The experiment commenced on 16 June. The plants were pinched 10 days after planting, and the experiment was terminated 5 Aug. Data collection was similar to that in Expt. 2, except internode length was not measured. The experiment was repeated on 4 Aug., terminating on 21 Sept. All plants received natural photoperiods.

Experimental repeats were pooled where no differences occurred between repeats. Data were subjected to analysis of variance (ANOVA), and treatment sums of squares were partitioned among preplanned orthogonal contrasts.

\section{Results}

Influence of spectral filters on nonpinched 'Spears' chrysanthemums. Plants grown under $\mathrm{CuSO}_{4}$ filters were shorter $(40 \%)$ (Table 2), with shorter internodes $(47 \%)$ and a higher leaf chlorophyll content $(22 \%)$ (Table 3 ) than controls. There were no height, internode, or chlorophyll differences between plants under the red- or blue-dye filters and controls.

There were no differences in stem diameter (data not shown), number of leaves per plant (16.5 to 16.9), and leaf area (280 to $312 \mathrm{~cm}^{2}$ ) between plants grown under $\mathrm{CuSO}_{4}$ or dye filters and controls.

Influence of spectral filters on pinched 'Spears' chrysanthemum. Pinched 'Spears' plants grown under $\mathrm{CuSO}_{4}$ filters were shorter $(46 \%)$ and had shorter internodes $(39 \%)$ than the controls (Table 2). There was no difference in internode length between plants grown under blue or red dye and the controls.

Table 2. Height and internode length of Dendranthema $\times$ grandflorum as influenced by spectral filters.

\begin{tabular}{|c|c|c|c|c|c|}
\hline \multirow[b]{4}{*}{ Filter } & \multicolumn{4}{|c|}{ Spears $^{z}$} & \multirow{4}{*}{ 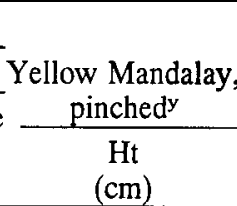 } \\
\hline & \multicolumn{2}{|c|}{ Nonpinched } & \multicolumn{2}{|c|}{ Pinched } & \\
\hline & \multicolumn{2}{|r|}{ Internode } & \multirow{2}{*}{\multicolumn{2}{|c|}{$\begin{array}{c}\text { Internode } \\
\mathrm{Ht} \\
\text { length } \\
(\mathrm{cm})(\mathrm{cm})\end{array}$}} & \\
\hline & $\begin{array}{c}\mathrm{Ht} \\
(\mathrm{cm})\end{array}$ & $\begin{array}{l}\text { length } \\
\text { (cm) }\end{array}$ & & & \\
\hline Red dye & 10.8 & 1.6 & 29.4 & 2.6 & 30.3 \\
\hline Blue dye & 11.2 & 2.0 & 29.6 & 2.8 & 29.3 \\
\hline $\mathrm{CuSO}_{4}$ & 7.6 & 0.9 & 15.5 & 1.6 & 16.9 \\
\hline Control & 10.6 & 1.7 & 28.7 & 2.6 & 28.6 \\
\hline \multicolumn{6}{|c|}{ Contrasts (probability) } \\
\hline Control vs. red dye & NS & NS & NS & NS & ** \\
\hline Control vs. blue dye & NS & NS & NS & NS & NS \\
\hline Control vs. $\mathrm{CuSO}_{4}$ & $* *$ & $* *$ & $* *$ & $* *$ & $* *$ \\
\hline
\end{tabular}

${ }^{2}$ Control: data pooled for water- and air-filled filters.

${ }^{y}$ Control: data for water-filled filters only.

Ns $*, * *$ Nonsignificant or significant at $P=0.05$ or 0.01 , respectively, within columns.

Table 3. Leaf chlorophyll content of Dendranthema $\times$ grandiflorum as influenced by spectral filters.

\begin{tabular}{|c|c|c|c|}
\hline \multirow[b]{3}{*}{ Filter } & \multicolumn{3}{|c|}{$\begin{array}{l}\text { Leaf chlorophyll } \\
\left(\mu \mathrm{g} \cdot \mathrm{cm}^{-2}\right)\end{array}$} \\
\hline & \multicolumn{2}{|c|}{ Spears ${ }^{z}$} & \multirow{2}{*}{$\frac{\text { Yellow Mandalay }}{\text { Pinchedy }}$} \\
\hline & Nonpinched & Pinched & \\
\hline Red dye & 33.6 & 34.3 & 36.7 \\
\hline Blue dye & 34.0 & 37.9 & 39.5 \\
\hline $\mathrm{CuSO}_{4}$ & 42.7 & 50.5 & 55.4 \\
\hline Control & 35.0 & 36.1 & 39.8 \\
\hline \multicolumn{4}{|l|}{ Contrasts (probability) } \\
\hline Control vs. red dye & NS & $* *$ & $*$ \\
\hline Control vs. blue dye & NS & NS & NS \\
\hline Control vs. $\mathrm{CuSO}_{4}$ & $* *$ & $* *$ & $* *$ \\
\hline
\end{tabular}

${ }^{7}$ Control: data pooled for water- and air-filled filters.

${ }^{y}$ Control: data for water-filled filters.

${ }^{\text {Ns }}, * * *$ Nonsignificant or significant at $P=0.05$ or 0.01 , respectively, within columns. 
Leaf chlorophyll concentration was higher in plants grown under $\mathrm{CuSO}_{4}(39 \%)$, less when plants were grown under red dye $(5 \%)$, and similar when plants were grown under blue dye when contrasted with plants that had no alteration in light quality (Table 3). Stem diameter did not vary between plants grown under $\mathrm{CuSO}_{4}$ or dye filters and the controls (data not shown).

Plants grown under $\mathrm{CuSO}_{4}$ had significantly fewer leaves (46\%) than the controls (Table 4). Plants grown under the dye filters did not differ from the controls. Capitula developed on all $\mathrm{CuSO}_{4}-$ filter-grown plants 10 days before similar structures were visible on plants from other treatments, but they were abnormal. At termination, all lateral branches in $\mathrm{CuSO}_{4}$-filter treatments had visible capitula, while plants of the other treatments had some vegetative and some reproductive buds (data not shown).

Leaf area of plants grown under $\mathrm{CuSO}_{4}$ solution or dyes did not differ from that of the controls (Table 4). For all treatments, primary lateral branches developed at all nodes below the pinch.

Influence of spectral filters on pinched Yellow Mandalay chysanthemums. Pinched 'Yellow Mandalay' plants were significantly shorter $(41 \%)$ when grown under the $\mathrm{CuSO}_{4}$ filter than under control filters. Plants grown under red-dye filters were taller $(6 \%)$ than the controls, but plants grown under the blue-dye filters were not different from controls (Table 2).

Leaf chlorophyll content was higher $(51 \%)$ in plants grown under the $\mathrm{CuSO}_{4}$ filter, lower $(8 \%)$ in plants under red-dye filters but similar in plants of the blue dye treatments when compared to controls (Table 3).

Leaf count per lateral was inconsistent between experiments. Plants grown under $\mathrm{CuSO}_{4}$ filters had fewer leaves than control plants in both experiments. Plants grown under blue or red dye were similar to controls in Expt. 1, but had more leaves than controls in Expt. 2 (Table 4). Capitula appeared 3 to 6 days earlier on plants grown under $\mathrm{CuSO}_{4}$ filters than in plants of other treatments. At termination of the first replication, only plants grown under $\mathrm{CuSO}_{4}$ filters had capitula visible on all lateral branches. At termination of the second replication, all lateral branches of all treatments had capitula.

Stem diameters and leaf areas of plants grown under $\mathrm{CuSO}_{4}$ solution or dye-grown plants were similar to those of control plants. Primary lateral branches developed at all nodes below the pinch for all treatments.

\section{Discussion}

Without exception, plants grown under the $\mathrm{CuSO}_{4}$ filters (increased $R: F R$, increased $P_{f r}: P_{t o t}$ ) were shorter (Table 2) and

Table 4. Leaf count and area on terminal branches of pinched Dendranthema $\times$ grandiflorum as influenced by spectral filters.

\begin{tabular}{|c|c|c|c|c|c|}
\hline \multirow[b]{3}{*}{ Filter } & \multicolumn{2}{|c|}{ Spears $^{z}$} & \multicolumn{3}{|c|}{ Yellow Mandalayy } \\
\hline & \multirow{2}{*}{$\begin{array}{l}\text { No. } \\
\text { leaves }\end{array}$} & \multirow{2}{*}{$\begin{array}{l}\text { Leaf area } \\
\left(\mathrm{cm}^{2}\right)\end{array}$} & \multicolumn{2}{|c|}{ No. leaves } & \multirow{2}{*}{$\begin{array}{l}\text { Leaf area } \\
\left(\mathrm{cm}^{2}\right)\end{array}$} \\
\hline & & & Expt. 1 & Expt. 2 & \\
\hline Red dye & 18.4 & 1302 & 22.0 & 16.6 & 1086 \\
\hline Blue dye & 18.5 & 1219 & 21.6 & 15.1 & 1046 \\
\hline $\mathrm{CuSO}_{4}$ & 9.8 & 1198 & 17.1 & 11.1 & 999 \\
\hline Control & 18.0 & 1304 & 21.5 & 13.8 & 1027 \\
\hline \multicolumn{6}{|l|}{ Contràsts (probability) } \\
\hline Control vs. red dye & NS & NS & NS & $* *$ & NS \\
\hline Control vs. blue dye & NS & NS & NS & $* *$ & NS \\
\hline Control vs. $\mathrm{CuSO}_{4}$ & $* *$ & NS & $* *$ & $* *$ & NS \\
\hline
\end{tabular}

${ }^{2}$ Control: data pooled for water- and air-filled filters.

${ }^{\mathrm{Y}}$ Control: data for water-filled filters.

Ns, $* * *$ Nonsignificant or significant at $P=0.05$ or 0.01 , respectively, within columns. had a higher leaf chlorophyll content (Table 3) than controls. These results are consistent with those of Mortensen and Strømme (1987), who determined that 'Refour' chrysanthemum, when grown nonpinched under $\mathrm{CuSO}_{4}$, were shorter and darker green than plants grown under other filters or natural light. At the beginning of our experiments, we were concerned that our chambers had one light-transmitting side and three reflective walls. Reflected light influences plant morphology, particularly if the surfaces reflect radiation selectively (Ballare et al., 1990; Kasperbauer, 1988). The reflective surfaces of our chambers were not selective, and the consistency of our results with those of Mortensen and Stromme's (whose chambers had four lighttransmitting sides) (Mortensen et al., 1987) suggests that chamber construction did not influence plant morphology.

Reduction in plant height was consistent with a reduction in internode length in Expts. 1 and 2 (Table 2). Although internodes were not measured in Expt. 3, calculating the average internode length using plant height and the number of leaves (nodes) per stem indicated that internodes were $25 \%$ to $35 \%$ shorter for plants grown in $\mathrm{CuSO}_{4}$-filtered chambers.

Plants that are grown in deficient photosynthetic light are tall, thin, and often etiolated (Cosgrove, 1986). The $\mathrm{CuSO}_{4}$ filters transmitted light with less intensity at the chlorophyll absorption maxima compared to control filters because some $\mathrm{R}$ light was not transmitted. However, even in a less photosynthetically active light environment (McCree, 1972), plants grown in the $\mathrm{CuSO}_{4}$-altered light environment were shorter and darker green than plants from the control filter chambers.

The reduction of height for pinched plants grown under $\mathrm{CuSO}_{4}$ filters was partially the result of fewer nodes developing, as indicated by reduced leaf count. Pinched plants grown under $\mathrm{CuSO}_{4}$ filters developed capitula sooner than other treatments, which caused cessation of node production. However, the capitula were abnormal and it is unlikely that they would have developed into normal flowers.

Chrysanthemums are quantative short-day plants and can be kept vegetative by long photoperiods or by interrupting long dark periods with light; however, vegetative buds eventually become reproductive (Cockshull, 1975). Flower buds induced under long days do not develop into normal flowers (Laurie et al., 1968). Interrupting the dark period with $\mathrm{R}$ light (increased $\mathrm{R}: \mathrm{FR}$, increased $\mathrm{P}_{\mathrm{fr}}: \mathrm{P}_{\text {tot }}$ ) is most effective in preventing floral initiation (Borthwick and Cathey, 1962).

Our study suggests that, during long photoperiods, increased $\mathrm{R}$ : FR promotes the change from vegetative to reproductive growth. However, a short photoperiod may be necessary for proper floral development.

Cultivars may also respond differently to increased R : FR. 'Spears' grown with increased R : FR developed capitula earlier and with fewer nodes than 'Yellow Mandalay' under a similar environment (Table 4). Response to photoperiodic flowering stimulus varies among cultivars (Langton, 1977). 'Yellow Mandalay' requires more short days to initiate flowers than 'Spears'. The cultivar difference may explain why 'Yellow Mandalay' grown under $\mathrm{CuSO}_{4}$ filters produced more nodes before floral initiation than 'Spears' even though the natural photoperiod was shorter and temperatures lower for 'Yellow Mandalay' than 'Spears'.

Decreased R : FR or a decrease in B light usually did not appear to affect reproduction. However, development of more nodes on plants grown under the dye filters in the second replication of pinched 'Yellow Mandalay' may indicate that reduced R : FR or decreased B light retards floral initiation under 
decreasing photoperiods (the replication ran from 5 Aug. to 21 Sept.).

The increase in chlorophyll in plants with an increase in $\mathrm{R}$ : FR compares favorably with another study where Chenopodium alba grown under an artificial light regime of increased $\mathrm{R}$ : FR had a higher chlorophyll content than plants grown under a decreased R : FR light regime (Holmes and Smith, 1977).

Plants grown under blue-dye filters did not differ in chlorophyll content from controls. However, plants grown under red-dye filters contained less chlorophyll than the controls. In another study (Leong et al., 1985), Asplenium australasicum grown under $\mathrm{R}$ light contained less chlorophyll than those grown under $\mathrm{B}$ or white light $(\mathrm{R}$ : FR unknown for regimes). Both studies indicate that $\mathrm{B}$ light promotes chlorophyll development.

Leaf area of plants grown under $\mathrm{CuSO}_{\mathrm{d}}$ filters did not differ from that of controls, although in the experiments with pinched plants, there were fewer leaves per stem. However, we noted that leaves on secondary lateral branches were more expanded on plants filtered by $\mathrm{CuSO}_{4}$ than on plants from the other treatments; these additional leaves would increase the total leaf area. The lack of differences in the experiment with nonpinched plants varies from the findings of Mortensen and Stromme (1987), who observed a reduction in leaf area for plants grown under $\mathrm{CuSO}_{4}$ filters. However, the durations of their experiments were longer and additional time may have allowed leaf area differences to develop. The PPF -between the two sites may be different. Mortensen and Stromme reported cumulative PPF over a 30-day period. Therefore, a precise comparison of PPF is not possible.

The red dye treatment created a blue-deficient environment. However, the plants did not differ in appearance from control plants (reduced chlorophyll levels were not visually apparent). This result differs from those of Dritz and Sager (1990), who reported that a B-light-deficient environment resulted in shadetype plants, i.e., plants were taller and weighed less than those grown under broad-spectrum (daylight fluorescence) lights. However, Dritz and Sager used a narrow-band light source (lowpressure sodium lamps $\lambda_{\max }=589 \mathrm{~nm}$ ). The transmittance a broad range of wavelengths above $500 \mathrm{~nm}$ in our study may have overcome the deficiency in B light. Likewise, plants under the blue-dye filter did not differ from controls. A filter that more closely mimics an understory environment (both $\mathrm{R}$ and $\mathrm{B}$ light removed) is necessary to induce visible shade-type morphology when broad bands of radiation are present. Reduced chlorophyll levels in red-dye-filtered plants indicate that anatomical changes may be occurring in red- and blue-dye-filtered plants.

We have demonstrated that growth of Dendranthema $\times$ grandiflorum can be manipulated by altering the light environment. Compact, dark-green plants desirable for pot-plant production can be produced under a filter that increases $\mathrm{R}$ : FR and increases $\mathrm{P}_{\text {fr }}: \mathrm{P}_{\text {tot }}$. However, unexpected reproductive and morphological responses indicate the need for further study. The filters we used did not allow us to investigate the effects of an environment deficient in both B and FR. Many photomorphogenic responses have been shown to depend on the presence of B light (Cosgrove, 1986).

\section{Literature Cited}

Ballare, C.L., A.L. Scopel, and R.A. Sanchez. 1990. Far-red radiation reflected from adjacent leaves: An early signal of competition in plant canopies. Science 247:329-332.

Borthwick, H.A. and H.M. Cathey. 1962. Role of phytochrome in control of flowering of chrysanthemum. Bet. Gaz. 123:155-162.

Borthwick, H.A., S.B. Hendricks, M.W. Parker, E.H. Toole, and V.K. Toole. 1952. A reversible photoreaction controlling seed germination. Proc. Natl. Acad. Sci. USA 38:662-666.

Cockshull, K.E. 1975. Premature budding in year-round chrysanthemums. Annu. Rpt. Glasshouse Crops Res. Inst. Rustington. 1974 (1975).

Cosgrove, D.J. 1986. Photomodulation of growth, p. 341-368. In: R.E. Kendrick and G.H.M. Kronenberg (eds.). Photomorphogenesis of plants. Martinus Nijhof, Boston.

Dritz, S.J. and J.C. Sager. 1990. Photomorphogenesis and photoassibilation.in soybean and sorghum grown under broad spectrum or blue-deficient light sources. Plant Physiol. 94:448454.

Duell-Pfaff, N. and E. Wellmann. 1982. Involvement of phytochrome and a blue light photoreceptor in UV-B induced flavenoid synthesis in parsley (Petroselinum hortense Hoffm. ) cell suspension cultures. Planta 156:213-217.

Eskins, K. and M. Duysen. 1984. Chloroplast structure in normal and pigment-deficient soybeans grown in continuous red or far-red light. Physiol. Plant. 61:351-356.

Holmes, M.G. and H. Smith. 1977. The function of phytochrome in the natural light environment. IV. Light quality and plant development. Photobiochem. Photobiol. 25:551-557.

Kasperbauer, M.J. 1988. Phytochrome regulation in adaptation of the photosynthetic apparatus and plant adaptation. Plant Physiol. Biochem. 26:519-524.

Langton, F.A. 1977. The response of early-flowering chrysanthemums to daylength. Sci. Hort. 7:277-289.

Laurie, A., D.C. Kiplinger, and K.S. Nelson. 1968. Commercial flower forcing. 7th ed. McGraw-Hill, New York.

Leong, T-Y., D.J. Goodchild, and J.M. Anderson. 1985. Effect of light quality on the composition, function, and structure of photosynthetic thylakoid membranes of Asplenium australasicum (Sm.) Hook. Plant Physiol. 78:561-567.

McCree, K.J. 1972. The action spectrum, absorptance and quantum yield of photosynthesis in crop plants. Agr. Meteorol. 9:191-196.

Moran, R. 1982. Formulae for determination of chlorophyllous pigments extracted with N,N-dimethylforrnamide. Plant Physiol. 69:13761381.

Moran, R. and D. Porath. 1980. Chlorophyll determination in intact tissues using N, N-dimethylformamide. Plant Physiol. 65:478-479.

Mortensen, L.M. and E. Stromme. 1987. Effects of light quality on some greenhouse crops. Sci. Hort. 33:27-36.

Mortensen, L. M., E. Stromme, Z. Sebesta, and D. Wenner. 1987. Growth chambers with control of light quality. Norwegian J. Agr. Sci. 1:1-5.

Pollock, R. K., R.E. Young, M.J. McMahon, and J.W. Kelly. 1990. Liquid spectral filtering for greenhouses: Regulation of photomorphogenesis in plants. Amer. Soc Agr. Eng. Paper 90-4036.

Sager, J. C., W.O. Smith, J.L. Edwards, and K.L. Cyr. 1988. Photosynthetic efficiency and phytochrome photoequilibria determination using spectral data. Trans. Amer. Soc. Agr. Eng. 31:18821887.

Vince-Prue, D. and A.E. Canham. 1983. Horticultural significance of photomorphogenesis, p. 518-544. In: W. Shropshire, Jr., and H. Mohr (eds.). Encycl. Plant Physiol. vol. 16. Springer-Verlag, New York. 